\title{
HYSTERETIC PERFORMANCE OF STEEL BEAM TO GANGUE CFST COLUMN CONNECTIONS WITH RING STIFFENERS UNDER LOW REVERSED CYCLIC LOADING
}

\author{
Guochang $\mathrm{Li}^{1^{*}}$, Wei Sun ${ }^{2}$ and Roberto T. Leon ${ }^{3}$ \\ ${ }^{1}$ School of Civil Engineering,Shenyang Jianzhu University, Shenyang 110168, China \\ ${ }^{2}$ Tianjin Chenli Technology CO., LTD, Tianjin 300400, China \\ ${ }^{3}$ School of Civil and Environmental Engineering, Georgia Institute of Technology \\ Atlanta: 30332-0355,U.S.A \\ *(Corresponding author: E-mail: cegcli@sjzu.edu.cn)
}

Received: 7 September 2010; Revised: 29 September 2010; Accepted: 12 October 2010

\begin{abstract}
In order to study the hysteretic performance of connections to gangue, tests of steel beams to gangue concrete-filled steel tube column (CFST) with ring stiffeners under low reversed cyclic loading were carried out including interior and exterior connections. The gangue is industrial waste dug out from under ground with coal. The curves of load and beam end displacement, strength degeneration, rigidity degeneration were drawn. On the basis of the above, the hysteretic behavior, energy dissipation, rigidity degeneration, strength degeneration and ductility of the joints were studied. It's shown that the joints of gangue CFST are featured with excellent quake-resistance and excellent hysteretic performance, energy dissipation and ductility. It will be referred to structure design and project application. This lays a good foundation in the application of gangue concrete-filled steel tubular structure.
\end{abstract}

Keywords: Gangue CFST, column to beam connection, reversed low cyclic loads, hysteretic performance, ductility

\section{INTRODUCTION}

Concrete-filled steel tubes (CFST) have been widely used in building construction [1]. The CFST column has many advantages compared with the ordinary steel or the reinforced concrete system due to its high-strength, stiffness, durability, ductility and better seismic resistance [2-5]. The composite members can make good use of mechanical property of steel and concrete. The main advantage of CFST columns in structural properties is due to the composite action between the constituent elements. The steel tube provides confining pressure to the concrete, which puts the concrete under a triaxial state of stress, and the strength of concrete is increased by the confining effect of the steel tube and prevents brittle fracture of infilled concrete. On the other hand, the steel tube is stiffened by the concrete core. This can prevent the inner local buckling of the steel tube, and increase the stability and strength of the column.

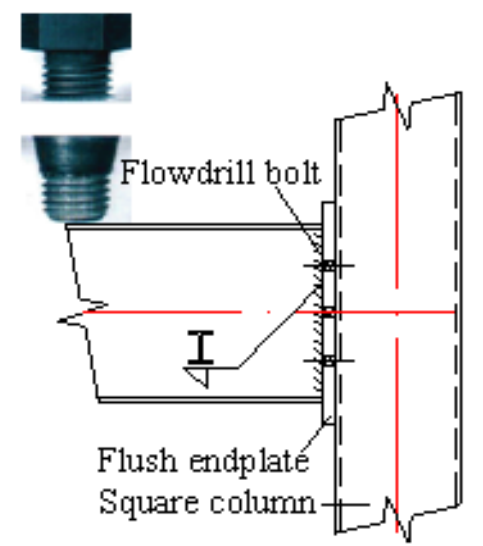

Figure 1. Connection of Hollobolt [7]

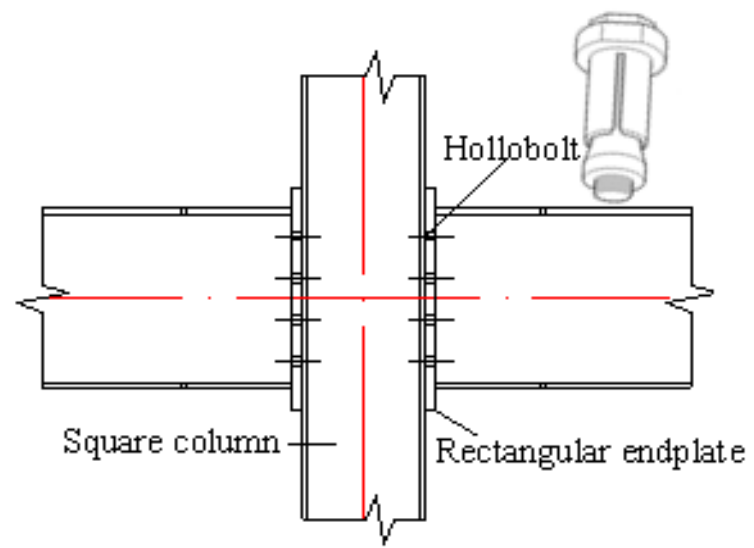

Figure 2. Connection of Flowdrill Bolt [10] 
It is well known that the performance of joints is the key parameter to assess behavior of multi-story frame structures. A large amount of researches have been carried out to study the behavior of beam-to-column connections both under the monotonic and cyclic loading [6-10]. Alostaz [6] presented a non-linear 3-D finite element study on a variety of details for connections to CFST. France [7] conducted a series of joint tests under monotonic loading to investigate the moment capacity and rotational stiffness of end plate connections to CFST columns with flowdrill connectors, as shown in Figure 1. Elremaily [8] conducted seven two-thirds scale connection specimen tests to study the behavior of through beam connection and develop the accompanying design provisions. Varma [9] reported the test results of eight monotonic beam-column specimens and eight cyclic beam-column specimens, which were square CFST beam-columns made from high-strength materials. Wang [10] studied the hysteretic behaviour of a type of connection for CFST columns, which was constructed using an approach of a flush end plate to circular or square concrete-filled hollow columns with blind bolts as shown in Figure 2. Gangue is a kind of industrial waste dug out from underground with coal. Compared to the ordinary concrete, gangue concrete features lighter weight, excellent heat-insulating capacity, and ductility. For this same compressive strength as ordinary concrete, the density of the corresponding gangue concrete is decreased by 20 percent. While gangue concrete is used primarily for floor systems, its use in columns can also reduce the weight of the building [11]. In this paper, half-scale connections between steel beams and gangue concrete-filled steel tube column with ring stiffeners were tested under reversed low cyclic loads. The seismic performances of the joints were analyzed. The results can be used as the references in practical projects.

\section{EXPERIMENTAL INVESTIGATION}

\section{$2.1 \quad$ Specimen Design}

Compared with other forms of welded connections to concrete filled columns, those incorporating ring stiffeners need to be carefully researched, as their performance is significantly influenced by their specific detailing [12-14]. In this research, interior and exterior connections, as shown in Table 1 and Figure 3, were used to study the performance of gangue concrete filled columns with ring stiffeners. The specimens were designed to represent connections in the lower stories of a typical multi-story building.

The column was a welded tube with a wall thickness of $6 \mathrm{~mm}$ and a slenderness of about 55; no local buckling problems were expected until substantial yielding had been reached. The beam was a welded I-shape with stiffeners welded $200 \mathrm{~mm}$ from the ends of the beam to facilitate the force transfer from the actuators. The ring stiffeners had the same thickness $(10 \mathrm{~mm})$ as the beam flanges. All welds were fillets, $6 \mathrm{~mm}$ thick. To confirm the mechanical properties of the steel used in the specimens, a tensile test of the steel was performed. Actual yield $\left(f_{y}\right)$ and ultimate stresses $\left(f_{u}\right)$, modulus of elasticity $\left(E_{\mathrm{s}}\right)$ are shown in Table 2 for the different thicknesses of the plates used (6 $\mathrm{mm}, 8 \mathrm{~mm}$ and $10 \mathrm{~mm}$, respectively).

Table 1. Dimensions

\begin{tabular}{|c|c|c|c|c|c|c|c|}
\hline \multicolumn{4}{|c|}{ Beam } & \multicolumn{3}{c|}{ Column } & \multicolumn{3}{c|}{ Stiffener Plate/ Weld } \\
\hline$b_{f}(\mathrm{~mm})$ & $t_{f}(\mathrm{~mm})$ & $t_{w}(\mathrm{~mm})$ & $H(\mathrm{~mm})$ & $(D \times t)(\mathrm{mm})$ & $b_{s}(\mathrm{~mm})$ & $t_{1}(\mathrm{~mm})$ & $h_{f}(\mathrm{~mm})$ \\
\hline 150 & 10 & 8 & 350 & $\Phi 325 \times 6$ & 80 & 10 & 6 \\
\hline
\end{tabular}

Note: $b_{f}$ is width of steel beam flange. $t_{f}$ is thickness of steel beam flange. $t_{w}$ is width of steel beam web. $h$ is thickness of steel beam. $b_{s}$ is width of ring stiffener. $t_{l}$ is thickness of ring stiffener. $D$ is diameter of steel tube. $t$ is thickness of steel tube shell. $h_{f}$ is welding size. 
Table 2. Average Material Performance of Q235B Steel

\begin{tabular}{|c|c|c|c|}
\hline Steel type & $f_{y} / M P a$ & $f_{u} / M P a$ & $E_{s} / G P a$ \\
\hline$t_{s}=6 \mathrm{~mm}$ & 324.8 & 459.9 & 197 \\
\hline$t_{s}=8 \mathrm{~mm}$ & 306.4 & 417.5 & 202 \\
\hline$t_{s}=10 \mathrm{~mm}$ & 347.1 & 578.2 & 204 \\
\hline
\end{tabular}

The concrete is $\mathrm{C} 30$ gangue concrete. When pouring the concrete, the concrete in the tubes was vibrated with poker vibration. After two weeks' curing, the $20 \mathrm{~mm}$ thickness steel plates with the size of $400 \mathrm{~mm} \times 400 \mathrm{~mm}$, were welded on the top of steel tubes.

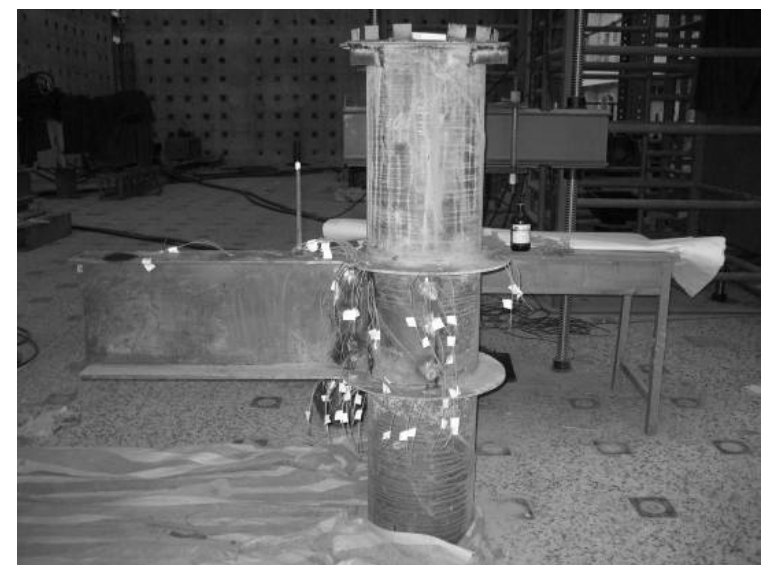

(a) Exterior Joint

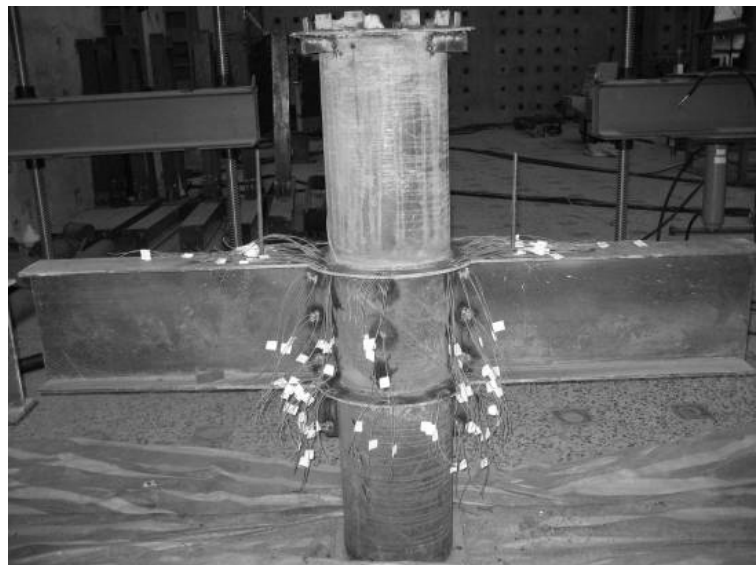

(b) Interior Joint

Figure 3. Specimen

\section{$2.2 \quad$ Experimental Setup and Loading Protocol}

The tests were carried out on $5000 \mathrm{kN}$ reaction frame in the Construction Engineering Laboratory of Shenyang Jianzhu University (Figure 4). A hinge was placed under the bottom of the gangue CFST column. The axial load was introduced by a $5000 \mathrm{kN}$ jack at the top of the gangue CFST column. The end of the steel beams were connected with $500 \mathrm{kN}$ hydraulic loading actuators with a $\pm 200 \mathrm{~mm}$ displacement range. Vertical reversed low cyclic loads were applied on the steel beam ends by the hydraulic actuators. The loading scheme was such so as to put opposite vertical deformations at the end of each beam.

To start the tests, a $1800 \mathrm{kN}$ axial compressive force was applied to the top of the concrete-filled steel tube using a $5000 \mathrm{kN}$ jack. This axial load corresponded to about 0.6 of the nominal axial strength of the column and was maintained through the whole experiment. Vertical reversed low cyclic loads were then imposed on the steel beams by electro-hydraulic actuators. 


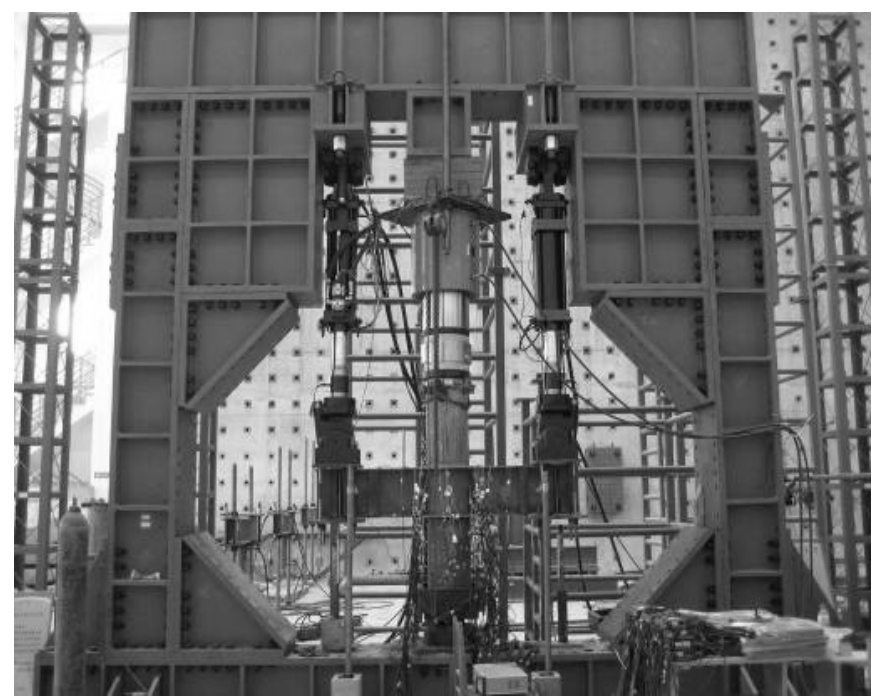

Figure 4. Experimental Device

For the exterior joint, the initial load was $10 \mathrm{kN}$ with $5 \mathrm{kN}$ added at each new load level. The specimen was cycled 3 times at each of these load levels until the load reached $160 \mathrm{kN}$. Afterwards, the test was controlled by beam end displacements, in increments of $2 \mathrm{~mm}$, until the load reached $280 \mathrm{kN}$ when the joint failed. For the interior joint, displacement control was used for the whole experiment. The initial displacement was $3 \mathrm{~mm}$, and $2 \mathrm{~mm}$ were added at every displacement increment, which consisted of 3 cycles. After yield was reached, the displacement change was increased to $3 \mathrm{~mm}$ and only 2 cycles were applied until the load reached $250 \mathrm{kN}$ when the joints failed.

\section{ANALYSIS OF SEISMIC PERFORMANCE}

\subsection{Hysteretic Behavior}

The hysteretic curves of the interior joint are shown in Figure 5 and Figure 6, while those for the exterior joint are shown in Figure 7.

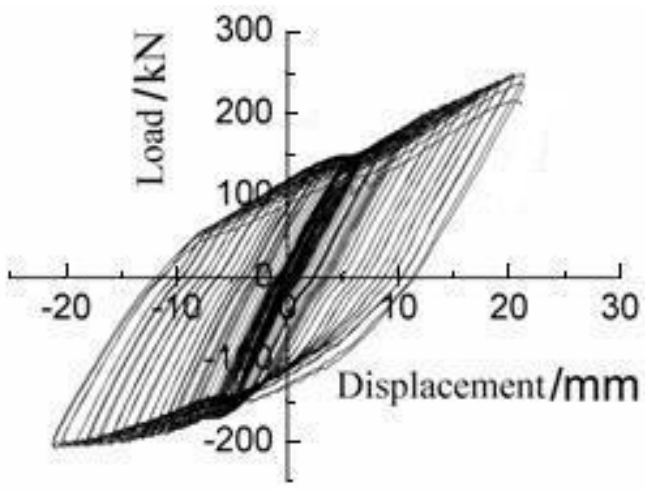

Figure 5. Right Beam of Interior Joint

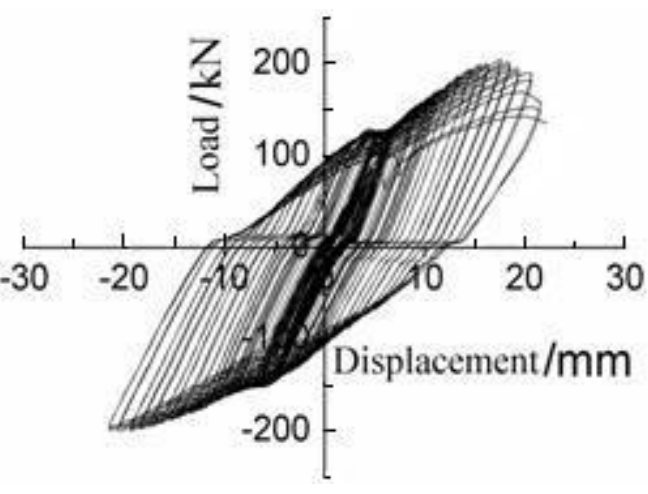

Figure 6. Left Beam of Interior Joint

It can be seen from Figure 5 through Figure 7 that the curves are almost perfectly elasto-plastic full, which shows the joints have excellent energy dissipation and hysteretic behavior. After the joints yield, the successive cycles at the same displacement coincide with a gradual strength decline. As the deformations increased beyond yield, every $0.3 \mathrm{~mm}$ increment resulted in a load increase of about $6.5 \mathrm{kN}$ until failure occurred. 
It can be seen from Figure 7, the shape of exterior joint's curve is approximate to that of the interior joint and shows the same hysteretic behavior as the interior joint.

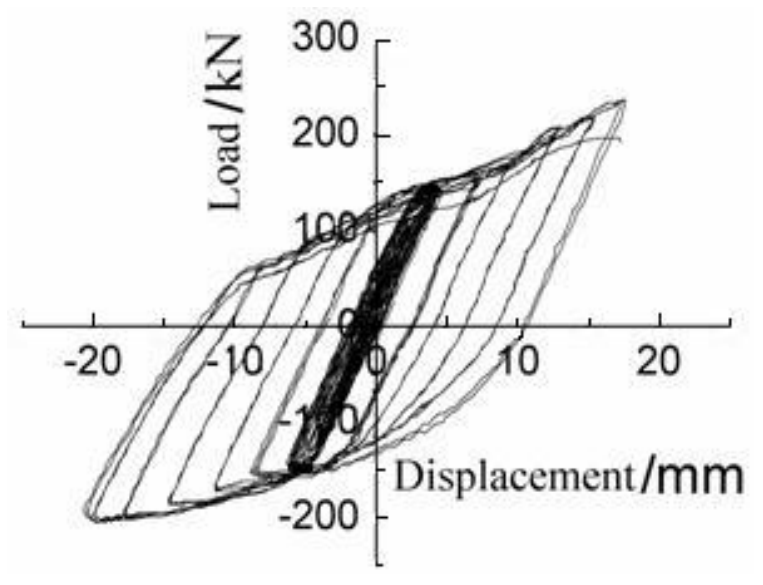

Figure 7. Beam End Load- Displacement Curve of Exterior Joint

\subsection{Ductility and Energy Dissipation}

An earthquake imparts energy to the structure and the structure reacts by absorbing and dissipating that energy. After the structure enters the non-linear range, the seismic performance depends primarily on the structural members' and joints' ability to dissipate energy without any sudden fracture. The area inside the load-displacement line (Figure 8) indicates the energy absorption capacity (the deformation energy sent out by the structure). The shadowed area between that curve and the horizontal axis is the energy dissipated. In Figure $8, \mathrm{~S}_{1}$ is the energy absorbed and $\mathrm{S}_{2}$ is the energy dissipated. $\mathrm{S}_{1}+\mathrm{S}_{2}$ is the total energy created by the horizontal force. $\Psi$ is energy dissipation ratio. $\Psi=\mathrm{S}_{1} /\left(\mathrm{S}_{1}+\mathrm{S}_{2}\right)$. The bigger the value of $\Psi$ is, the more energy is dissipated through frictional resistance or local damage (such as cracking or rotations of the plastic hinges) [15].

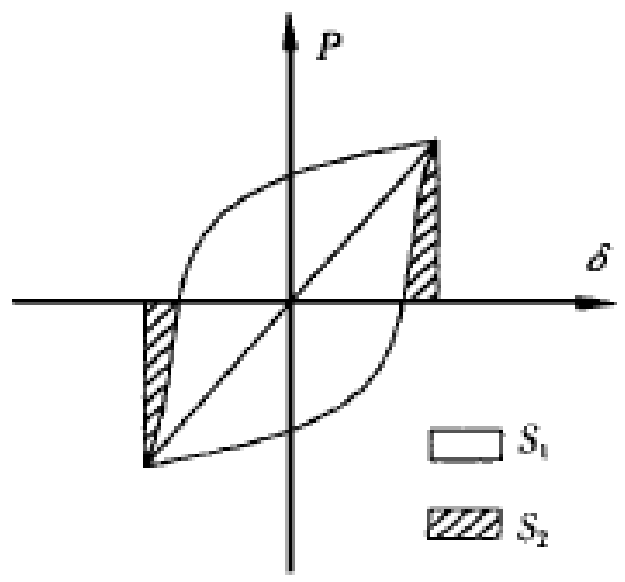

Figure 8. Hysteretic Circle

Another measure of the cyclic response is the displacement ductility factor $\delta$. The joint ductility factor is generally givens as $\delta=\delta u / \delta y$, where $\delta y$ is yield displacement and $\delta u$ is the ultimate displacement. Table 3 shows $\Psi$ and $\delta$ for the two specimens. The value of $\delta$ is greater than 4 in all cases, indicating moderately good ductility. 
Table 3. $\Psi$ and $\delta$ of the Models

\begin{tabular}{|c|c|c|c|}
\hline models & Right beam interior & Left beam interior & Exterior \\
\hline$\Psi$ & 0.816 & 0.818 & 0.807 \\
\hline$\delta$ & 4.602 & 4.476 & 4.119 \\
\hline
\end{tabular}

\subsection{Strength Degradation}

Strength degradation defined as the progressive loss of strength with cycling at a given deformation level [16]. Strength degradation can be represented by bearing capacity degradation factor $\lambda_{i}$ given by:

$\lambda_{i}=\frac{Q_{j, \max }^{i}}{Q_{j, \max }^{1}}$

In this equation, $Q_{j, \max }^{i}$ is the load value of the peak point of $i$ load cyclic when $\delta$ value is $j . Q_{j, \max }^{1}$ is the load value of the peak point of the first load cyclic when $\delta$ value is $j$.

According Figure 9 shows the capacity degradation factor-displacement curve. It can be seen from Figure 9 that capacities degrade slowly when the displacements are less than $8 \mathrm{~mm}$. When the displacements are larger than $8 \mathrm{~mm}$, degradation factor begins to decline as the strength of the models begin to degenerate. Strength degradation for the exterior joint is slightly faster than for the interior joint. The reason is that exterior joint loading was controlled by the force before the joint yields. So, the displacement is larger. The main reason of strength degradation is that the bearing capacities of steel beams degrade.

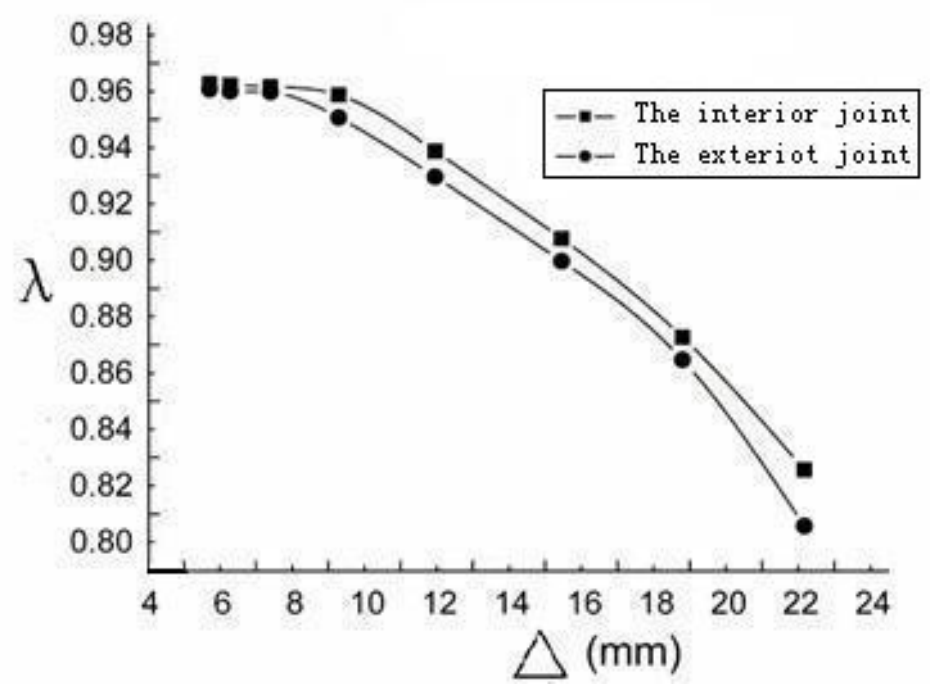

Figure 9. Strength Degradation Curve 


\subsection{Rigidity Degradation}

Joint stiffness influences not only the accuracy of the structure calculations but also inter-story displacements. Large joint distortion can increase inter-story drifts appreciably, and lead to non-structural failures. With cycling at a constant amplitude, the joint stiffness degrades. The less reduced rate is, the better energy dissipation is. In experiment, rigidity degradation can be researched through unvaried amplitude loading usually. In order to qualify the member rigidity degradation under low reversed cyclic loading, rigidity degradation should be represented by cyclic linear rigidity in the same load step. Cyclic linear rigidity can be calculated through the equation below [17]:

$$
K_{i}=\frac{\sum_{i=1}^{n} P_{j}^{i}}{\sum_{i=1}^{n} \Delta_{j}^{i}}
$$

In this equation, $K_{i}$ is cyclic linear rigidity, $P_{j}^{i}$ is the load value of the peak point of the i load cyclic when $\delta$ value is $\mathrm{j}$, and $\Delta_{j}^{i}$ is the displacement value of the peak point of the i load cyclic when $\delta$ value is $j$.

The P- $\triangle$ curve, which is obtained through restoring force experiment, put forwards that rigidity is related with displacement and the number of cyclic. Rigidity changes all the time. Rigidity degradation is that peak point displacement increase as the number of cyclic increase when maintaining the same peak point load value. In order to analyze earthquake reaction, tangent rigidity should be replaced by secant rigidity [15]. This method is used in this paper to define rigidity degradation. According to the loading process, rigidity degradation is the secant slope of the hysteretic curve cyclic when structure on the same load, Figure 10 shows this.

According to rigidity degradation definition, rigidities of the 2 models in the experiment were calculated and rigidity degradation curves were also drawn, Figure 11 shows them.

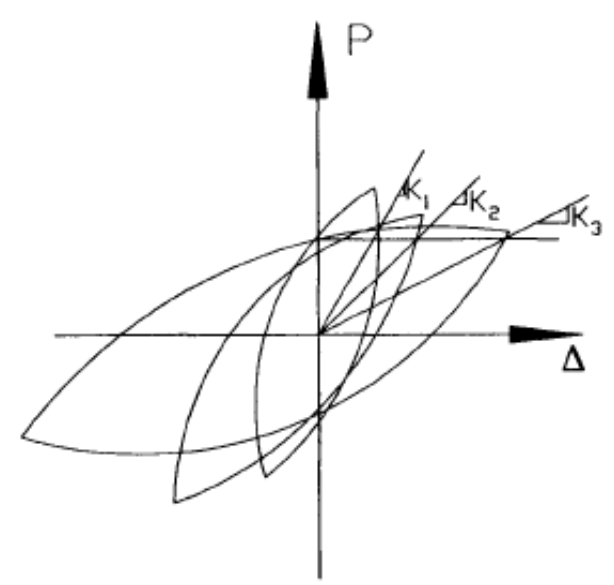

Figure 10. Rigidity Degradation Sketch

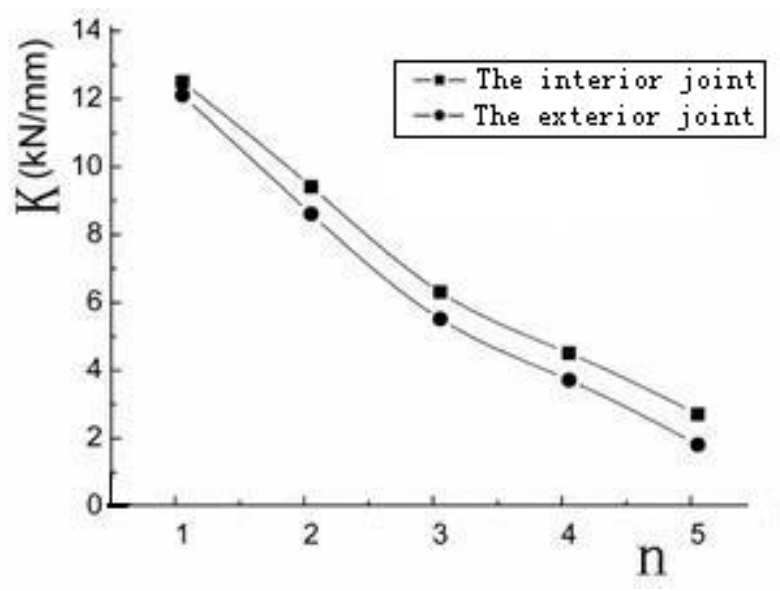

Figure 11. Rigidity Degradation Curves 
In above curves, $\mathrm{n}$ is the number of cyclic. The rigidities of the 2 models degrade gradually. Rigidity degradation of the exterior joint is faster than the interior joint. The reason is that stability of the exterior joint is worse than the interior joint. In each load step cyclic after the model yield, the interior joint's displacement at the beam end is larger. Otherwise, interior joint loading was controlled by the displacement in the whole process. So, its rigidity degrades gradually.

\section{CONCLUSIONS}

(1) Joints of steel beams to gangue concrete-filled steel tube column with ring stiffeners are excellent in seismic performance under low reversed cyclic loading. Joints have good strength, ductility and stiffiness.

(2) The steel tube column and the frame joint are content with designing concepts of the strong column and weak beam. The joints are safe and the designing method is feasible.

(3) On the other hand, the gangue used as aggregate can reduce the weight of building, make non-renewable resources, gravel, sustainable to be developed. So, gangue concrete filled steel tubular composite structure can be called green structure.

\section{ACKNOWLEDGEMENTS}

This project was supported by supported by Technology Program of Ministry of Housing and Urban-Rural Development (2010-k3-35) \& Research Program of Liaoning Province Office of Education (LS2010134).

\section{REFERENCES}

[1] Morino, S. and Tsuda, K., "Design and Construction of Concrete-filled Steel Tube Column System in Japan”, Earthquake Engineering and Engineering Seismology, 2003, Vol. 4, No. 1, pp. 51-73.

[2] Usami, T., Ge, H.B. and Saizuka, K., "Behavior of Partially Concrete-filled Steel Bridge Piers Under Cyclic and Dynamic Loading”, Journal of Constructional Steel Research, 1997, Vol. 41, No. 2, pp. 121-136.

[3] Ding, F.X. and Yu, Z.W., "Behavior of Concrete and Concrete-filled Circular Steel Tubular Stub Columns at Constant High Temperatures", Journal of Central South University of Technology (English Vesion), 2006, Vol. 37, No. 6, pp. 726-732.

[4] He, A.L. and He, Y.B., "Stress-strain Relation of Core Concrete of Axially-loaded Steel Tubular Columns Filled with Steel-reinforced Concrete", Journal of Central South University of Technology, 2010, Vol. 41, No. 1, pp. 341-346.

[5] Liang, Q.Q. and Fragomeni, S., "Nonlinear Analysis of Circular Concrete-filled Steel Tubular Short Columns Under Cccentric Loading", Journal of Constructional Steel Research, 2010, Vol. 66, pp. 159-169.

[6] Alostaz, Y.M. and Schneider, S.P., "Analytical Behavior of Connections to Concrete-filled Steel Tubes”, Journal of Constructional Steel Research, 1996, Vol. 40, No. 2, pp. 95-127.

[7] France, J.E., Davison, J.B. and Kirby, P.A., "Strength and Rotational Response of Rigid Connections to Tubular Columns Using Flowdrill Connectors", Journal of Constructional Steel Research, 1999, Vol. 50, No. 1, pp. 1-14. 
[8] Elremaily, A. and Azizinamini, A., "Experimental Behavior of Steel Beam to CFT Column Connections", Journal of Constructional Steel Research, 2001, Vol. 57, pp. 1099-1119.

[9] Varma, A.H., Ricles, J.M., Sause, R. and Lu, L.W., "Seismic Behavior and Modeling of High-strength Composite Concrete-filled Steel Tube (CFT) Beam-columns", Journal of Constructional Steel Research, 2002, Vol. 58, pp. 725-758.

[10] Wang, J.F., Han, L.H. and Uy, B., "Hysteretic Behaviour of Flush End Plate Joints to Concrete-filled Steel Tubular Columns", Journal of Constructional Steel Research, 2009, Vol. 65, pp. 1644-1663.

[11] Li, G.C. and Ren, Q.S., "Dynamic Performance of Pure Bending of Gangue Concrete-filled Steel Circular Tubualr", Sixth International Conference on Advances in Steel Structures, Hong Kong, China, Dec. 2009.

[12] Federico, M.M., "Moment Resistant Connections of Steel Frames in Seismic areas - Design and Reliability", London : E \& FN Spoon, 2000.

[13] Beutel, J., Thambirtnam, D. and Perera, N., "Cyclic Behavior of Concrete filled Steel Tubular Column to Steel Beam Connection”, Engineering Structures, 2002, Vol. 24, No. 11, pp. 29-38.

[14] Ge, H.B., Susantha, K.A.S. and Satake, Y. et al., "Seismic Demand Predictions of Concrete-filled Steel Box Columns", Engineering Structures, 2003, Vol. 25, pp. 337-345.

[15] Tao, Zhong. and Yu, Q., "New Type of Composite Structure Column: Test, Theory and Methods", Beijing: Science Press, 2006.

[16] Zhong, S.T. and Bai, G.L., "Beam to Column Frame Connection of Tall Building Composite Structure Analysis and Design”, Beijing: Renmin Communication Press, 2006.

[17] He, Y.Q., "Theoretical Analysis and Experimental Research on New Type of Joint of Concrete filled Steel Tubular Column with RC Beam. Master degree thesis", Nanjing: School of Civil Engineering, Hehai University, 2006. 